\title{
Axotomy-induced neurotrophic withdrawal causes the loss of phenotypic differentiation and downregulation of NGF signalling, but not death of septal cholinergic neurons
}

\author{
Oscar M Lazo ${ }^{1}$, Jocelyn C Mauna ${ }^{1,3}$, Claudia A Pissani ${ }^{1}$, Nibaldo C Inestrosa ${ }^{2}$, Francisca C Bronfman ${ }^{1 *}$
}

\begin{abstract}
Background: Septal cholinergic neurons account for most of the cholinergic innervations of the hippocampus, playing a key role in the regulation of hippocampal synaptic activity. Disruption of the septo-hippocampal pathway by an experimental transection of the fimbria-fornix drastically reduces the target-derived trophic support received by cholinergic septal neurons, mainly nerve growth factor (NGF) from the hippocampus. Axotomy of cholinergic neurons induces a reduction in the number of neurons positive for cholinergic markers in the medial septum. In several studies, the reduction of cholinergic markers has been interpreted as analogous to the neurodegeneration of cholinergic cells, ruling out the possibility that neurons lose their cholinergic phenotype without dying. Understanding the mechanism of cholinergic neurodegeneration after axotomy is relevant, since this paradigm has been extensively explored as an animal model of the cholinergic impairment observed in neuropathologies such as Alzheimer's disease.

The principal aim of this study was to evaluate, using modern quantitative confocal microscopy, neurodegenerative changes in septal cholinergic neurons after axotomy and to assess their response to delayed infusion of NGF in rats.

Results: We found that there is a slow reduction of cholinergic cells labeled by ChAT and p75 after axotomy. However, this phenomenon is not accompanied by neurodegenerative changes or by a decrease in total neuronal number in the medial septum. Although the remaining axotomized-neurons appear healthy, they are unable to respond to delayed NGF infusion.

Conclusions: Our results demonstrate that at 3 weeks, axotomized cholinergic neurons lose their cholinergic phenotype without dying and down-regulate their NGF-receptors, precluding the possibility of a response to NGF. Therefore, the physiological role of NGF in the adult septal cholinergic system is to support phenotypic differentiation and not survival of neurons. This evidence raises questions about the relationship between transcriptional regulation of the cholinergic phenotype by retrograde-derived trophic signaling and the transcriptional changes experienced when retrograde transport is impaired due to neuropathological conditions.
\end{abstract}

\section{Background}

Basal forebrain cholinergic neurons (BFCN) account for most of the cholinergic innervation of the hippocampus and cortical mantle, and have a key role in the regulation of synaptic activity and modulation of memory and attention in rodents, primates and humans [1-5].

\footnotetext{
* Correspondence: fbronfman@bio.puc.cl

'Department of Physiology, Neurobiology Unit, Center of Ageing and Regeneration (CARE), Nucleus Millennium in Regenerative Biology (MINREB), Faculty of Biological Sciences, Pontificia Universidad Catolica de Chile, Alameda 340, CP 8331010, Santiago, Chile
}

The physiology of septal cholinergic neurons is regulated by the trophic support offered by their target, the hippocampus. Disconnection of septal cholinergic neurons from their target by an experimental transection of the fimbria-fornix, reduces the number of neurons positive for cholinergic markers such as choline acetyl transferase (ChAT) [1,6-13]. One of the best-studied trophic factors for septal cholinergic neurons is nerve growth factor (NGF). Levels of NGF mRNA and protein are consistently detected in the hippocampal formation and cortex. In addition, it is well established that NGF is 
retrogradely transported from the hippocampus to the septal area and that intracerebroventricular application of NGF or intracerebral transplant of NGF-releasing cells prevents the reduction in the proportion of neurons positive for cholinergic markers after axotomy $[14,15,7,12,16-18]$.

The mechanisms of cholinergic neurodegeneration after axotomy are poorly characterized. Most of the studies performed have considered the loss of ChAT, acetyl cholinesterase (AChE) or p75 neurotrophin receptor (p75) immunoreactivity as an analogue of neurodegeneration [19-22], ruling out the possibility that neurons lose their cholinergic phenotype without dying.

Septal cholinergic neurons express two different types of receptors for NGF: the tyrosine kinase receptor TrkA (TrkA), which specifically binds NGF; and the p75 neurotrophin receptor (p75), which binds all neurotrophins. Together, TrkA and p75 activate pro-survival gene expression and influence growth [23]. Conversely, p75 signaling mediates neuronal death by apoptosis in different neuronal systems, including neurodegenerative models such as corticospinal axotomy and seizure-induced apoptosis of septal cholinergic neurons [24-29]. Activation of NGF receptors up-regulates several cholinergicspecific genes, such as the high-affinity choline transporter and the acetylcholine synthesizing enzyme ChAT, which share a common gene locus with the vesicular acetylcholine transporter (VAChT) [30-33].

Axotomy-induced cholinergic decay in the basal forebrain has been explored as an animal model for cognitive decline due to cholinergic impairment, similar to that observed in aging and neuropathologies such as Alzheimer's disease (AD) [34,35]. Due to its role as a neurotrophic factor for cholinergic neurons, NGF gene therapy is currently in phase 1 clinical trial for AD treatment [12,36-39].

The principal aim of this research was to re-evaluate, using modern quantitative confocal microscopy, neurodegenerative changes in septal cholinergic neurons after axotomy and to assess their response to delayed infusion of NGF in rats. To pursue this goal, we have performed a stereological analysis of the rat septal area, using quantitative double- and triple-labeling confocal microscopy analysis of axotomized brains with different cell markers and neurodegenerative labels at different timepoints after axotomy. Furthermore, we have assessed the response of cholinergic neurons to delayed infusion of NGF three weeks after axotomy.

As shown before, we found that there is a slow reduction in the number of immunoreactive cholinergic cells after axotomy $[6,40]$. However, this phenomenon is not accompanied by neurodegenerative changes or a decrease of total neuronal number in the medial septum. Although the remaining axotomized-cells appear healthy, they are unable to respond to delayed NGF infusion. These results demonstrate that axotomized cholinergic neurons down-regulate their NGF receptors, precluding the possibility of a response to NGF.

Our results suggest that the physiological role of NGF in the adult septal cholinergic system is to support phenotypic differentiation and not neuron survival. This evidence raises the question of how the connection with the target regulates the transcription of cholinergic markers in vivo and of which other factors could re-induce the cholinergic phenotype when retrograde transport is impaired due to neuropathological conditions such as $\mathrm{AD}$ and Down syndrome $[38,41,42]$.

\section{Results}

Expression profile of ChAT and p75 immunopositive septal cholinergic neurons after axotomy of the fimbriafornix: a time course study

It is well established that after two weeks of unilateral axotomy of the fimbria-fornix, the number of ChATpositive neurons ipsilateral to the lesion decreased to about $30 \%$ as compared to the contralateral side $[8,10,13,43]$. To quantify cholinergic cell loss, we used two different antibodies against well-established cholinergic markers, ChAT and p75. We found a similar slow reduction in ChAT and p75 immunopositive cells as well as diminished acetyl cholinesterase (AChE) fiber staining in the hippocampus (Figure 1). We observed that the number of cells labeled with ChAT or p75 decreased with similar kinetics over time (7 to 21 days after axotomy). However, there were always more cells labeled with p75, suggesting that some cholinergic cells had lost ChAT expression but continued expressing p75 (Figure 1C).

This finding was supported by quantitative confocal studies where both ChAT and p75 were labeled in the same section and the number of cells that were colabeled with both proteins was quantified. On the nonaxotomized side, co-localization between the two labels was about $90 \%$, whereas 14 days after the lesion, just $60 \%$ of the neurons labeled with p75 were also positive for ChAT (Figure 2). In the septal nucleus, there are also GABAergic neurons that could be re-expressing p75 due to the axotomy. In a triple immunofluorescence with ChAT, p75 and parvalbumin 'a commonly used GABAergic marker $[44,45]$ - there was a non-significant number of cells co-labeled with parvalbumin and p75 (Figure 3), ruling out the possibility that the neurons expressing just p75 are GABAergic.

\section{Septal cholinergic neurons do not degenerate through} apoptotic cell death after axotomy

p75 is an apoptotic receptor that mediates cell death of cholinergic neurons in other paradigms $[27,46]$. However, cholinergic neurons from p75 knockout mice are not 


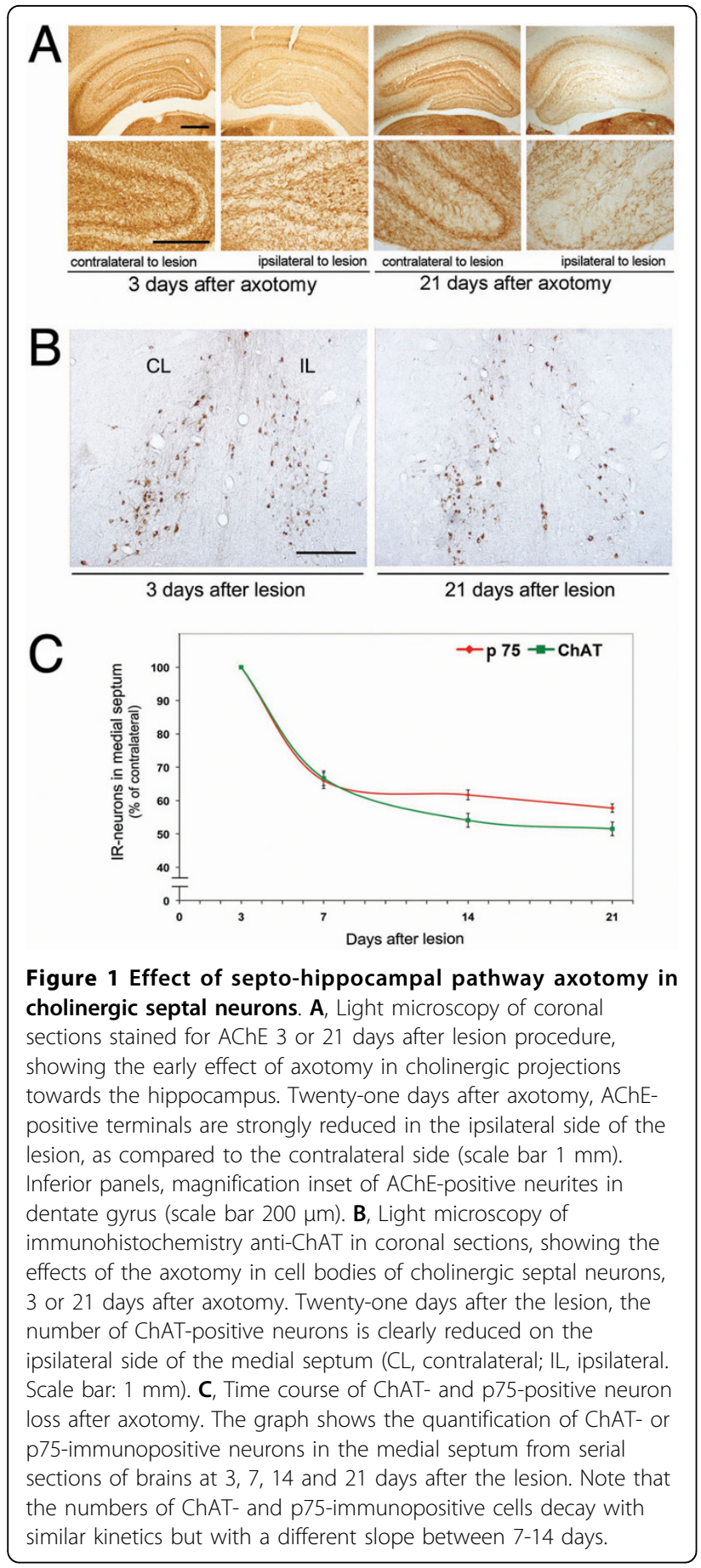

protected from the reduction in numbers of cholinergic neurons after axotomy [19], suggesting that p75 does not play a role in cholinergic neurodegeneration after axotomy or that there is no death of cholinergic cells after the fimbria-fornix lesion. To further support this possibility, we performed triple immunostaining against ChAT, p75 and p53 or cleaved caspase- 3 in rat brain sections starting from day one up to two weeks after axotomy.
Although there were positive reactions for cleaved caspase-3 or p53 in the septal nucleus after axotomy, they did not co-localize with ChAT, p75 or the general neuronal marker NeuN (Figure 4A, B, C). In addition, neurons were not labeled with Fluorojade $\mathrm{C}$, a well-known marker of degenerating neurons [27,47] (Figure 4D). To further identify the nature of the cells that were positive for cleaved caspase-3 (Figure 4C), double immunostaining was performed with NeuN [48,49] and the glial fibrillary acidic protein (GFAP) to label astroglia. We could clearly identify the astroglia as the cell type co-localizing with cleaved caspase-3 (Figure 4C).

To standardize the immunostaining of cleaved caspase- 3 and p53, we induced cell death by injecting $\mathrm{H}_{2} \mathrm{O}_{2}$ to the medial septum. In these conditions, cleaved caspase- 3 and p53 clearly labeled damaged neurons as indicated by their co-localization with altered Neurotrace labeling (Additional file 1). Neurotrace is a fluorescent Nissl staining that only labels neurons and does not co-localize with markers of different glial cells such as astro, micro or oligodendroglia (Additional file 2).

\section{There is no loss of neurons in the medial septum three}

\section{weeks after axotomy}

In order to determine whether there is a non-apoptotic neuronal degeneration after axotomy in the septal nucleus, triple immunostaining with two neuronal markers -Neurotrace and NeuN-plus the astroglial marker GFAP was performed in sections of 3-week axotomized rat brains and control brains. The total number of neurons in the septal nucleus was quantified as defined in Figure 5. Our analysis indicated that there was no difference between the total numbers of neurons from the contralateral vs. ipslateral side to the lesion (Figure 5). It is still possible that the axotomy performed to the rat brain may have an effect in the total number of neurons in the contralateral side to the lesion. To address this point, we have quantified the total number of neurons in the medial septum -as define in Figure 5- in a healthy brain comparing the left and the right sides of the medial septum. We found, no differences in the total number of neurons between the left and the right sides of healthy brains nor differences between these numbers and the numbers of neurons found in lesioned brains (Table 1). These results, together with the lack of cleaved caspase-3, p53 and Fluorojade C staining 3 weeks after axotomy, strongly support the notion that axotomy of the fimbria-fornix does not induce neuronal death in the medial septum. Our results are also consistent with the study of van der Zee and Hagg in p75 knockout $(\mathrm{KO})$ mice. The authors studied the potential participation of p75 in the death of axotomized cholinergic cells [19], and found that the absence of p75 does not prevent septal ChAT-positive cell loss. However, these results should be taken with caution, since 

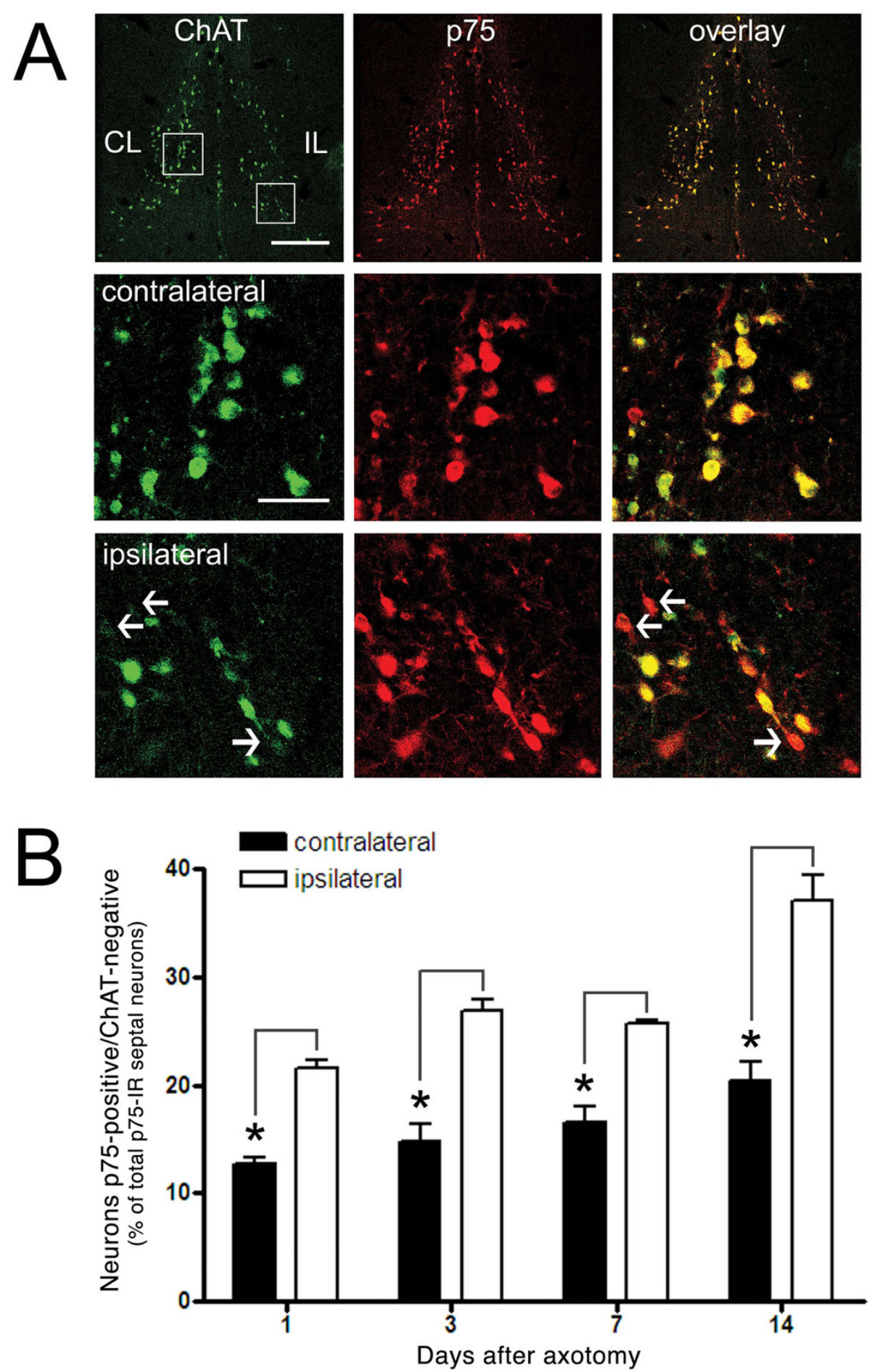

Figure 2 The number of neurons that are positive only for p75 is increased in the ipsilateral side after axotomy. A, Confocal microscopy of double-immunofluorescence anti-ChAT/anti-p75 reveals an increase in the number of neurons that are positive only for p75 at different times after the axotomy. The superior panel is a panoramic view of the medial septum at 14 days after axotomy (scale bar: $1 \mathrm{~mm}$ ). The central and inferior panels are magnification insets (scale bar: $200 \mu \mathrm{m}$ ) of neurons contralateral and ipsilateral to the lesioned side, showing p75positive and ChAT-negative cells as indicated by the white arrows. B, The graph shows the percentage of total septal neurons expressing p75 that are p75-positive and ChAT-negative at 1, 3, 7 or 14 days after axotomy. Black bars represent the control side of the septum and white bars represent the side ipsilateral to the lesion. Asterisk indicates significance level $p<0.05$. 


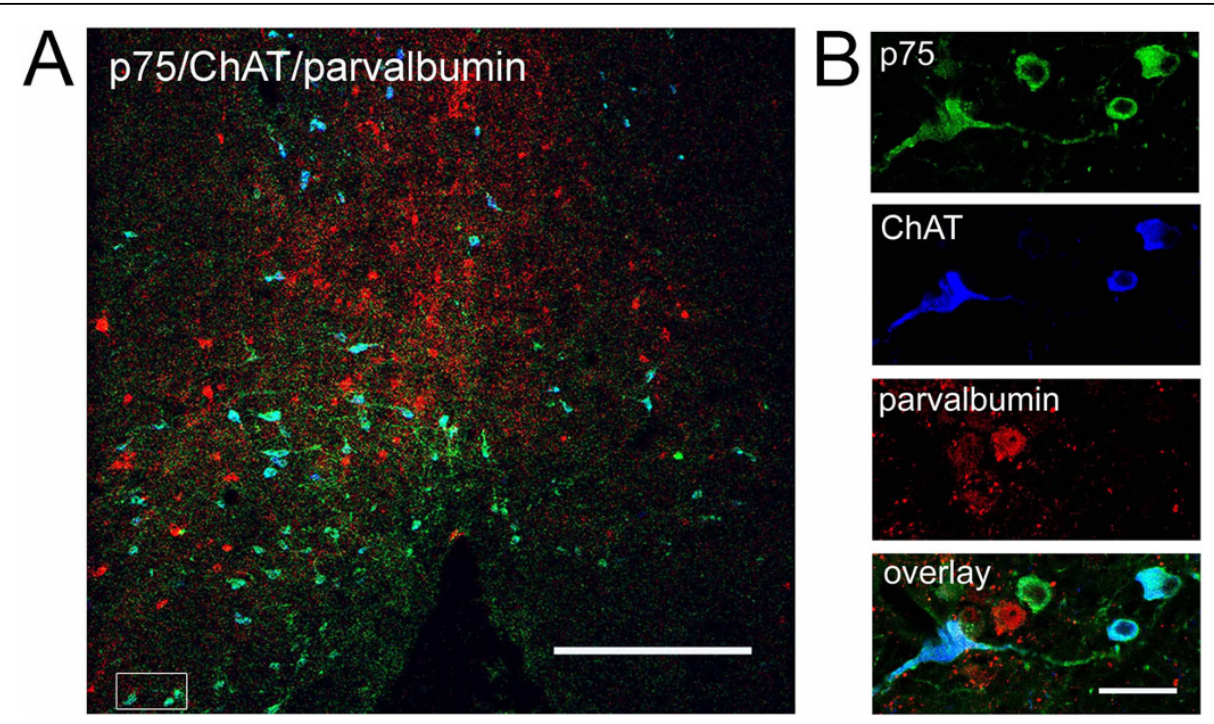

Figure 3 p75-positive and ChAT-negative neurons are not GABAergic. Confocal microscopy of triple-immunofluorescence anti-ChAT/antip75/anti-parvalbumin shows no significant colocalization of GABAergic marker and p75. Left, a panoramic view of the medial septum (scale bar: $1 \mathrm{~mm}$ ) and panel showing a magnification inset of a representative group of neurons from triple-labeled sections (scale bar: $300 \mu \mathrm{m}$ ).

KO mice still express an alternatively spliced form of p75 [50].

\section{Response of axotomized septal neurons to delayed NGF infusion}

It is possible that the neurons that survive after axotomy are still able to re-express the cholinergic markers if trophic support is restored. Normally, axotomized cholinergic cells respond to NGF when the infusion of NGF is concurrent with lesion surgery, as shown in Figure 6A and described previously $[6,20,40]$. However, when NGF was infused 3 weeks post-axotomy, neurons did not respond and there were no increase in cholinergic cell number, as is observed when NGF is infused simultaneously to the lesion (Figure 6B). This correlates with the fact that there is a reduction in the number of TrkA-positive cells on the ipsilateral side, and all remaining TrkA-positive cells are also ChAT positive (Figure 6C). This suggests that the lack of response to NGF is due to down-regulation of TrkA. The effect is not explained by an incomplete diffusion of NGF to the ipsilateral side of the septum, since there are neurons that are clearly positive for NGF: they show a punctate pattern of staining, which is consistent with receptormediated NGF uptake (Figure 6A, B). These results are apparently different from those reported by Hagg and colleagues $[19,40]$ in mice. They found a small recovery of ChAT immunopositive cells in the ipsilateral side after delayed NGF treatment, in comparison to untreated animals. However, in agreement with our findings, van der Zee and Hagg observed that a significant number of neurons $(60 \%)$ were not capable of responding to a delayed NGF infusion paradigm.

\section{Discussion}

In the present study, we report the response of basal forebrain cholinergic cells to axotomy based on the use of time-course analyses, multiple immunostainings and quantitative confocal microscopy. Our results establish that cholinergic cells do not respond to disconnection of their target, as induced by axotomy, with apoptotic celldeath, but rather with down-regulation of the neurotransmitter-synthesizing enzyme ChAT and NGF receptors. As opposed to other nervous system injury models, such as corticospinal and olfactory bulb axotomy and kainic acidinduced cytotoxicity [27,29,51], p75 receptor does not play a role in axotomy-induced cholinergic cell neurodegeneration. Of note, like septal cholinergic cells, Purkinje cells in the cerebellum are also resistant to axotomy [52]. We are yet far from explaining the differences in the response to axotomy between cholinergic and Purkinje neurons and cortico-spinal and olfactory bulb neurons. One possibility is that cholinergic neurons became resistant to the withdrawal of neurotrophic factor, as postulated by Snider [53] for sensory neurons. It is well established that during development, or in neonates, axotomy or neurotrophic deprivation induces apoptotic cell death of dorsal root ganglia (DRG) neurons [54]. However, adult DRGs 'as opposed to embryonic DRGs- differentially express DeltaNp73a, a pro-survival protein related to the $\mathrm{p} 53$ family [55]. The expression of this protein renders cells resistant to axotomy or neurotrophic factor withdrawal. Another gene involved in protection of neurons after injury is the heat shock protein Hsp27, which directly or indirectly activates the Akt survival pathway. The expression of Hsp27 inhibits JNK-mediated apoptosis in superior cervical 


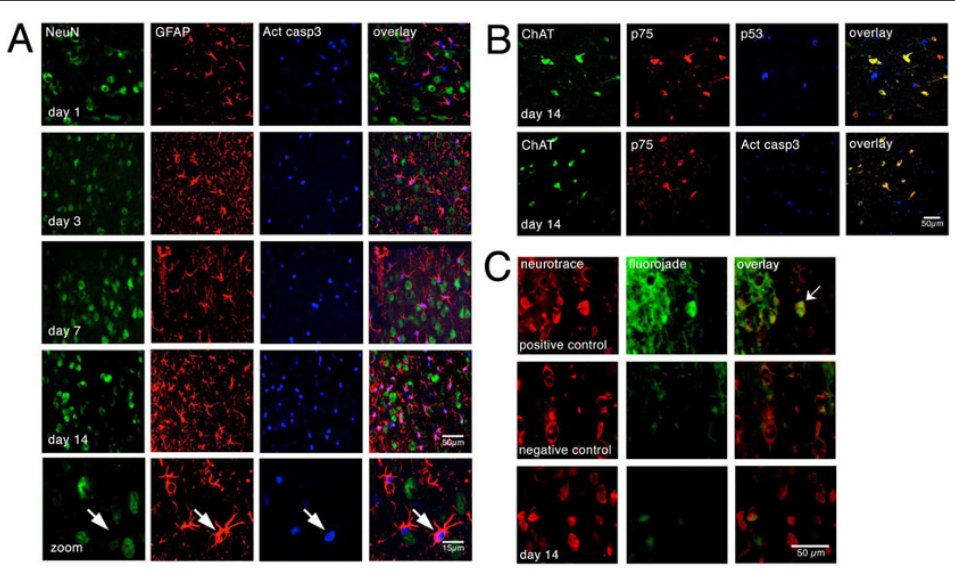

Figure 4 Cholinergic septal neurons do not undergo apoptosis after axotomy. A, Triple-immunofluorescence against Neu- $\mathrm{N}$ (neuronal marker), GFAP (astroglial marker) and activated Caspase-3 shows no colocalization of the apoptotic marker with neurons at different time points $(1,3,7,14$ days) after axotomy. There is an increase in the number of cells that are immunopositive for activated caspase- 3 with time. The correlation between GFAP and activated Caspase-3 suggests that astrocytes are undergoing apoptosis (scale bar: $50 \mu \mathrm{m}$ ). B, Tripleimmunofluorescence against ChAT, p75 and p53, shows no colocalization of p53 (an early apoptotic marker) with p75- or ChAT-immunopositive neurons in the brains of axotomized rats 14 days after the axotomy. Confocal microscopy (scale bar: $50 \mu \mathrm{m}$ ). Triple-immunofluorescence against ChAT, p75 and activated caspase-3 shows no colocalization of activated Caspase-3 and p75 or ChAT immunopositive neurons after 14 days of axotomy. Confocal microscopy (scale bar $50 \mu \mathrm{m}$ ). C, Axotomized septal neurons are not labeled with Fluorojade $\mathrm{C}$ (a specific staining for degenerating neurons). Superior panel, a brain section from a rat injected in medial septum with $100 \mathrm{mM} \mathrm{H}_{2} \mathrm{O}_{2}$ was stained with Neurotrace and Fluorojade $\mathrm{C}$ as a positive control. The arrow indicates a degenerating neuron. Center panel, double-labeling with Neurotrace and Fluorojade in a brain section from an untreated rat. Inferior panel shows no colocalization of Neurotrace and Fluorojade C in medial septal neurons 14 days after axotomy (scale bar $50 \mu \mathrm{m}$ ).
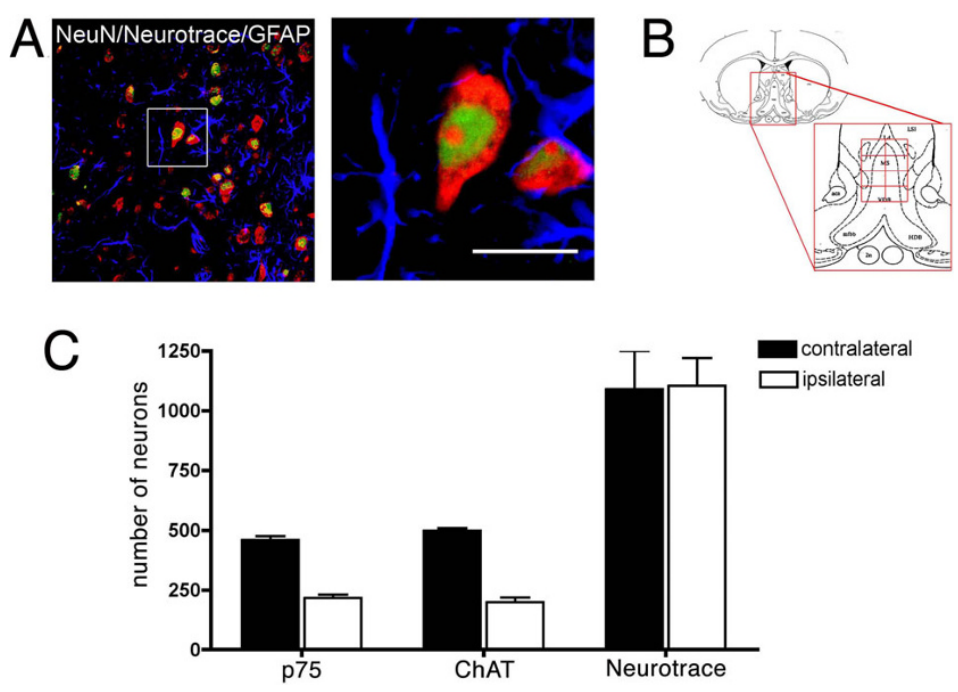

Figure 5 There is no difference between the number of septal neurons when comparing the ipsilateral and contralateral regions of brains 21 days after axotomy. A, Left, confocal microscopy of triple labeling for Neurotrace (red), NeuN (green) and GFAP (blue) from the septal region of a lesioned brain. In order to assure that we were counting only neurons, we used two neuronal markers and an astrocytic marker (GFAP). Right, inset magnification of a neuron (scale bar: $80 \mu \mathrm{m}$ ) showing the Neurotrace and NeuN labeling profiles. B, Diagram illustrating the area of the medial septum (MS) that was considered for the quantification of cholinergic or total number of neurons (adapted from Rat Brain Atlas [65]). Each side of the total area was divided to 4 fields and then photographed and manually quantified. The anatomical landmarks used to define the MS are also indicated (see Experimental Methods). cc, corpus callosum; LV, lateral ventricle; aca, anterior commissure. C, Quantification of p75-positive, ChAT-positive and total septal neurons. Comparison of the number of septal neurons on contralateral and ipsilateral sides shows differences in the numbers of p75- and ChAT-immunopositive neurons, but no significant difference in total number of neurons $(n=5$; Student's t-test, $p>0.001, \pm S D) 21$ days after axotomy. 
Table 1 Total number of neurons in the medial septum.

\begin{tabular}{lllll}
\hline \multicolumn{5}{c}{ Number of neurons } \\
\hline Brain Hemisphere & Left $( \pm$ SD) & Right $( \pm$ SD) & Number of brains considered & Number of sections per brain \\
\hline Lesioned brain & $1090 \pm 319(\mathrm{CL})$ & $1103 \pm 233(\mathrm{IPL})$ & 5 & 3 \\
\hline Healthy brain & $1085 \pm 137$ & $1057 \pm 82$ & 3 & 3 \\
\hline
\end{tabular}

Neurons from the medial septum, as delineated in Figure 5, of brains from axotomized rats (lesioned brains) and control rats (healthy brains) were labeled with neurotrace and their number quantified. $\mathrm{CL}$, contralateral to the lesion. IPL, ipsilateral to the lesion.

ganglion neurons and adult DRGs [56,57]. It would be interesting to study whether adult cholinergic cells express DeltaNp73 and/or Hsp27. As mentioned above, other adult neurons such as corticospinal neurons are not resistant to axotomy and die in a p75-dependent fashion, probably because they fail to express any of the abovementioned survival programs after injury $[29,58]$.

One unexpected observation of our study was that only GFAP-positive cells were immunopositive for cleaved caspase-3. GFAP positive cells appear hypertrophic and strongly stained in the whole tissue, thus revealing a generalized astrogliosis. This reaction may account for a global inflammatory response to the lesion which may cause apoptosis of astrocytes, as has been reported in other injury models or in neurodegenerative diseases [59]. It is interesting that apoptotic cell death in the septal nucleus after axotomy was previously reported by electron microscopy studies [21]. However, the quality of the microscopy precludes discrimination of the cell type. Therefore, it is possible that the apoptotic septal cells mentioned in this study are glial cells rather than neurons.

Disruption of the connection between septal cholinergic cells and the hippocampus results in down-regulation of ChAT, but not neuronal death. A consequence of this is that the basal forebrain cholinergic cells affected during aging and in pathological states such as AD may still be alive. Therefore, the possibility of restoring the cholinergic phenotype by identifying new factors that influence cholinergic function would be an interesting point for further investigation. Some candidates are the BMPs and neurosteroids. Studies by Lopez-Coviella and colleagues have shown that BMP-9 is a robust factor for induction and maintenance of the cholinergic phenotype in vitro [60,61], which also synergizes with NGF to enhance neuronal transcriptional response [30,62]. In addition, neurosteroids such as estrogen and retinoic acid have also been shown to upregulate the cholinergic phenotype in the septal basal forebrain [63,64].

Taking this into account, future studies could search for components that up-regulate the cholinergic phenotype in the absence of NGF receptors. This may open new avenues for therapeutic intervention for the treatment of the cholinergic deficit observed in AD.

\section{Methods}

\section{Animals}

Male Sprague-Dawley rats were maintained with free access to water and fed with normal rat chow at the Pontificia Universidad Catolica animal care facilities. Experimental procedures were in accordance with institutional standards for care and use of laboratory animals.

Rats weighting 280-300 g were anesthetized (xylazine $2 \mathrm{mg} /$ ketamine $20 \mathrm{mg}$ i.p. and lidocaine 9\% locally applied on the ears) and positioned in a stereotaxic apparatus. Coordinates were calculated based on the Paxinos and Watson atlas of the rat brain [65]. After surgery, the animals were injected i.p with antibiotic (enrofloxacine $7.5 \mathrm{mg}$ ) and maintained under observation and temperature control for one hour. For histological preparation of brain tissue, rats were transcardially perfused with $250 \mathrm{ml}$ of $0.9 \% \mathrm{NaCl}$, and $250 \mathrm{ml}$ of $4 \%$ paraformaldehyde (PFA) in phosphate buffer. After extraction, the brain was post-fixed overnight in $4 \%$ PFA, left on $30 \%$ sucrose for 24 hours, and coronally sectioned $(40 \mu \mathrm{m})$ on a cryostat.

\section{Fimbria-fornix transection}

Unilateral axotomy of the septo-hippocampal pathway was induced by aspirative lesion of the fimbria-fornix, as has been previously described [66]. In brief, anesthetized rats were positioned in a stereotaxic apparatus and a small piece of skull was removed at the stereotaxic coordinates $1.8 \mathrm{~mm}$ caudal to the bregma, and $0.0-4.0 \mathrm{~mm}$ lateral to the midline. After excision of the dura, we performed a syringe aspiration of the dorsal fornix-fimbria. We also used a syringe to aspirate part of the cingulate and parietal cortices, $3.5 \mathrm{~mm}$ ventral from the brain surface. Rats were sacrificed 3-21 days after axotomy.

$\mathrm{H}_{2} \mathrm{O}_{2}$ injection in the medial septum

Two $\mu$ l of $0.1 \mathrm{M} \mathrm{H}_{2} \mathrm{O}_{2}$ were injected in the septal areas of two adult rats: $0.35 \mathrm{~mm}$ rostral to bregma, $0.5 \mathrm{~mm}$ lateral to midline and $7 \mathrm{~mm}$ dorso-ventral. After 72 hours, rats were perfused and brain sections were prepared for immunostaining.

\section{Intracerebroventricular infusion of NGF}

Artificial cerebrospinal fluid (ACSF) containing $150 \mathrm{mM}$ $\mathrm{NaCl}, 1.8 \mathrm{mM} \mathrm{CaCl}_{2}, 1.2 \mathrm{mM} \mathrm{MgSO} 4,2 \mathrm{mM} \mathrm{KH} \mathrm{PO}_{4}$ and $10 \mathrm{mM}$ glucose, $\mathrm{pH} 7.4$ with or without NGF (Alomone Labs, Jerusalem, Israel) at a concentration of 0.2 


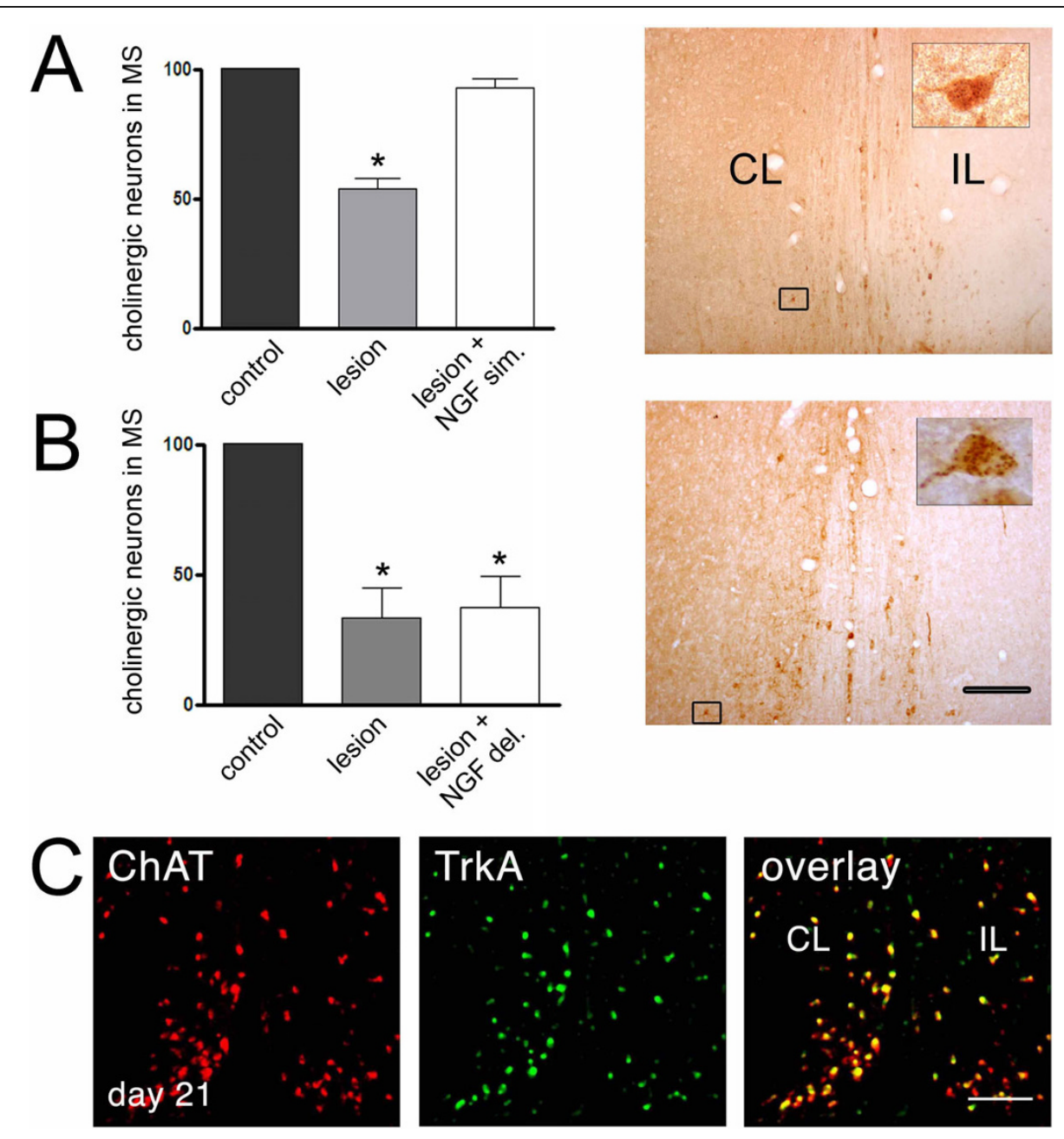

Figure 6 Effect of intracerebroventricular infusion of NGF on the loss and recovery of the cholinergic phenotype. A, The septohippocampal path was axotomized and NGF-infusion was performed for two weeks. Left, quantification of septal cholinergic neurons in the lesioned side as compared to the contralateral side in untreated animals (control), lesioned animals (lesion) and lesioned animals braininfused with NGF (lesion + NGF sim.). Right, light microscopy of anti-NGF immunohistochemistry showing the wide distribution of infused NGF and uptake of NGF by septal neurons. Exogenous NGF infused right after axotomy protects cholinergic cells from ChAT-loss. B, The septohippocampal path was axotomized and 3 weeks after the axotomy (delayed NGF-infusion), NGF was infused for two additional weeks. This procedure did not protect cholinergic cells from ChAT-loss, contrary to the protection observed with simultaneous infusion. C, Confocal microscopy of double immunofluorescence against TrkA and ChAT showing the colocalization of these markers in septal neurons 21 days after axotomy (inferior panel). There are no ChAT-negative cells positive for TrkA, suggesting that neurons cannot respond to NGF 3 weeks postaxotomy due to down-regulation of NGF receptors.

$\mu \mathrm{g} / \mathrm{ml}$ was infused for 14 days $(2.5 \mu \mathrm{L} /$ hour $)$ by using a brain infusion kit (Alza Corp., Palo Alto, CA), connected to a model 2002 Alzet osmotic pump (Alza Corp., Palo Alto, CA), as described previously [6]. The cannulae and connector tube were filled with ACSF only or with ACSF plus NGF and attached to a loaded pump. Using the arm of the stereotaxic apparatus, the cannula was lowered into the brain at left ventricle coordinates $(0.8$ $\mathrm{mm}$ caudal to bregma, $1.2 \mathrm{~mm}$ lateral to midline and $3.5 \mathrm{~mm}$ ventral to the brain surface) and finally anchored to the skull with a screw and glued with dental acrylic. Axotomized rats were infused for 14 days immediately after axotomy (simultaneous NGF infusion) or 3 weeks after axotomy (delayed NGF infusion).

\section{AChE enzyme-histochemistry}

Serial coronal cryostat sections $(40 \mu \mathrm{m})$ were collected in $0.1 \mathrm{M}$ phosphate buffer ( $\mathrm{pH} 7.4$ ), washed in $65 \mathrm{mM}$ sodium maleate ( $\mathrm{pH}$ 6.0) and incubated for staining, as floating sections, for 1 hour at room temperature in $0.05 \mathrm{mg} / \mathrm{mL}$ acetylthiocholine iodide, 0.1 tetra-isopropyl-pyrophosphatamide, $0.05 \mathrm{mM}$ potassium ferricyanide, $0.3 \mathrm{mM} \mathrm{CuSO}_{4}, 0.5 \mathrm{mM}$ sodium citrate, and 65 $\mathrm{mM}$ sodium maleate ( $\mathrm{pH} 6.0)$, as described previously [46]. 


\section{Immunohistochemistry}

ChAT immunohistochemistry was performed as follows: (i) 15 min incubation in $0.03 \% \mathrm{H}_{2} \mathrm{O}_{2}$ in $0.1 \mathrm{M}$ Tris- $\mathrm{HCl}$, $150 \mathrm{mM} \mathrm{NaCl}, \mathrm{pH} 7.4$ (TBS) to block endogenous peroxidase; (ii) 30 min incubation at $4^{\circ} \mathrm{C}$ with $0.4 \%$ Triton$\mathrm{X} 100$ in TBS; (iii) $1.5 \mathrm{hr}$ incubation at $4^{\circ} \mathrm{C}$ with $0.2 \%$ Triton-X100, 5\% rabbit serum, 5\% BSA in TBS; (iv) 48 hr incubation at $4{ }^{\circ} \mathrm{C}$ with goat anti-ChAT antibody (Chemicon, CA, USA) diluted 1:300 in TBS plus $0.2 \%$ Triton-X100 and 5\% serum; (v) $1.5 \mathrm{hr}$ incubation at room temperature with biotin-conjugated rabbit antigoat IgG (1:300 in TBS; DakoCytomation, CA, USA); (vi) $1 \mathrm{hr}$ incubation with peroxidase-conjugated avidin ABC (DakoCytomation, CA, USA), followed by visualization of peroxidase activity with diaminobenzidine (DAB, $1 \mathrm{mg} / \mathrm{mL}$ ) $0.01 \% \mathrm{H}_{2} \mathrm{O}_{2}$ in TBS.

NGF immunohistochemistry was preceded by $15 \mathrm{~min}$ incubation in $50 \%$ ethanol, followed by the same protocol already described. Rabbit anti-NGF (Alomone Labs, Jerusalem, Israel) and rabbit anti-p75 (Upstate, NY, USA) were used at 1:300 and 1:500, respectively.

\section{Immunofluorescence}

Single or double-immunofluorescence was performed in floating brain sections as follows: (i) $15 \mathrm{~min}$ incubation in TBS; (ii) 15 min incubation in $\mathrm{NaBH}_{4} 10 \mathrm{mg} / \mathrm{mL}$; (iii) 30 min incubation at $4^{\circ} \mathrm{C}$ with $0.4 \%$ Triton-X100 in TBS; (iv) $1.5 \mathrm{hr}$ incubation at $4^{\circ} \mathrm{C}$ in $0.2 \%$ Triton-X100, $5 \%$ rabbit serum, 5\% BSA in TBS; (v) $48 \mathrm{hr}$ incubation at $4{ }^{\circ} \mathrm{C}$ with primary antibodies in $0.2 \%$ Triton-X100 $5 \%$ serum in TBS; (v) $1.5 \mathrm{hr}$ incubation at room temperature with fluorochrome-conjugated (Molecular Probes, Oregon, USA) or biotin-conjugated secondary antibodies (directly labeled antibodies were used 1:100 in TBS; antibodies amplified with biotin were diluted 1:300 in TBS), followed by 1.5 hours with fluorochrome-conjugated streptavidin (Molecular Probes, Oregon, USA). Mouse anti-Neu-N, anti-parvalbumin, and rabbit antiGFAP (labeling astroglia) antibodies were from Chemicon (Temecula, CA, USA). Mouse anti-CD11B (labeling microglia) was from Serotec, Oxford, UK. Rabbit polyclonal anti-OMgp (labeling oligodendroglia) was kindly provided by Dr. Colman (McGill University, Montreal, Canada). Polyclonal rabbit anti-cleaved caspase-3 was purchased from Cell Signaling Technology (Danvers, MA, USA). Monoclonal anti-p53 was from Santa Cruz Biotechnologies, CA, USA; polyclonal rabbit anti-TrkA antibody was kindly provided by Dr. L. Reichardt (University of California, San Francisco, CA, USA).

\section{Neurotrace and Fluorojade $\mathrm{C}$ staining}

Staining with fluorescent probes such as Neurotrace (fluorescent Nissl stain; Molecular Probes, Oregon, USA) and Fluorojade $C$ (specific marker for degenerating neurons; Chemicon, CA, USA) was performed as indicated by the manufacturers' instructions. Briefly, Neurotrace staining was performed after immunostaining by incubating brain sections for $20 \mathrm{~min}$ in a 1:200 dilution of Neurotrace in TBS. Sections were then rinsed, air-dried and mounted in Mowiol. Fluorojade staining was performed after Neurotrace as follows: brain sections were rinsed twice in TBS, re-hydrated for 2 minutes in distilled water and incubated for $10 \mathrm{~min}$ utes in $0.06 \%$ potassium permanganate. Finally, brain sections were washed for 2 minutes in distilled water and incubated for 10 minutes in $0.0002 \%$ Fluorojade $C$ solution in $0.1 \%$ acetic acid. Sections were immediately rinsed in distilled water, mounted, air-dehydrated, cleared with xylene and mounted in Entellan.

\section{Septal cholinergic cell counting}

The cholinergic cell count was performed essentially as described before [46] but modified for rat. Septal cholinergic neurons were defined by using anatomical landmarks in accordance with the rat brain atlas [65]. The ventral border of the medial septum was defined dorsal to the anterior commissure, and the rostral beginning was indicated by the meeting of the body of the corpus callosum at the midline. The caudal end of the septal nucleus was defined by the appearance of the fornix and the midline crossing of the anterior commissure. Four 40- $\mu \mathrm{m}$-thick coronal sections were examined for each rat ( $\mathrm{n}=4$ animals per time point), starting $0.7 \mathrm{~mm}$ caudal to bregma and $200 \mu \mathrm{m}$ apart, to avoid counting the same cell twice. For each section, immunopositive neuronal profiles (labeled with ChAT or p75) were counted on images digitized on an Olympus BX51 (Tokyo, Japan) optic microscope (40× objective), equipped with a CoolSnap-Pro digital camera (Media Cybernetics, Maryland, USA) and connected to an image analysis system based on Image-pro express software, version 5.1.0.12 (Media Cybernetics, Maryland, USA). The pictures were analyzed by using the Sigmascan software (SPSS; Chicago, IL, USA). The criterion for identifying ChAT- or p75- immunopositive cells was the appearance of a clear nucleus or, in cases when staining was too dark, clear neuronal morphology.

\section{Total neuron counts}

The anatomical landmark we used to define the medial septum nucleus (MS) was the same previously described for septal cholinergic cell counting. Three 40- $\mu$ m-thick coronal sections were considered for each rat $(\mathrm{n}=5$ animals), starting $0.7 \mathrm{~mm}$ caudal to the bregma and 200 $\mu \mathrm{m}$ apart, to avoid counting the same cell twice. The sections were double-stained with Neurotrace (fluorescent Nissl stain; Molecular Probes, Oregon, USA; as indicated by the manufacturer instructions) and antiNeu-N diluted 1:250 and developed with a secondary antibody conjugated to Alexa 488 fluorochrome. The 
area for counting was defined as a triangle: its base was a horizontal line crossing the middle point of the left and right anterior commissures, and its sides were the anatomical borders of the medial septum, as shown in Figure 5. Eight pictures of this area (four per side) were obtained using a confocal microscope with a $63 \times$ objective and scanned with an optical section of $10.3 \mu \mathrm{m}$. The criterion used to define healthy neurons was Neu$\mathrm{N}$ and/or Neurotrace staining: cells with cytoplasmic and nucleolar staining, as shown in Figure 3, were counted as healthy neurons. Other patterns of staining corresponding to neurons undergoing degeneration $[67,68]$, such as perinuclear Nissl (or chromatolytic) staining and eccentric distribution of the nucleus, were scarcely observed after axotomy (and clearly observed after $\mathrm{H}_{2} \mathrm{O}_{2}$ injection) and were not considered.

\section{Confocal microscopy}

Confocal images for counting double-labeled ChAT/p75 neurons or total neurons labeled with Neurotrace and Neu-N were collected on a Zeiss LSM Pascal 5 (including a triple laser module [Arg 458/488/514 nm, HeNe $543 \mathrm{~nm}, \mathrm{HeNe} 633 \mathrm{~nm}$; Carl Zeiss, Thornwood, NY]) connected to an inverted microscope (Axiovert 2000). A lower objective $(20 \times)$ was used to have a panoramic view of the septal nucleus of each brain section and a higher magnification objective $(63 \times)$ was used to scan the total area as described in Figure 5. The images were analyzed using the SigmaScan software (SPSS, Chicago, IL, USA).

\section{Data analysis}

Comparisons between the axotomized or unlesioned side of the septum were statistically validated by performing a Student's t-test to determine significance level $(\mathrm{p}<0.05)$. The analyses were performed using the septum contralateral to the lesioned side as a control $(100 \%)$.

Additional File 1: Validation of $\mathrm{p} 53$ and activated-Caspase 3 as neurodegeneration markers in the septum. Confocal microscopy of coronal sections triple-labeled with anti-activated caspase-3, anti-p53 and Neurotrace (fluorescent Nissl stain) was performed in septa of rats injected with $\mathrm{H}_{2} \mathrm{O}_{2}(100 \mathrm{mM})$ or unlesioned control rats. The unlesioned brain shows no reactivity for p53 or activated-caspase 3 , while in the $\mathrm{H}_{2} \mathrm{O}_{2}$-injected brain there are labeled neurons in the region of injection. Labeling neurons (Neurotrace-positive cells) with anti-p53 and antiactivated-caspase 3 , validates these antibodies as neurodegeneration markers. Additional file: descriptions text (including details of how to view the file, if it is in a non-standard format).

Click here for file

[http://www.biomedcentral.com/content/supplementary/1750-1326-5-5S1.pdf]

Additional File 2: Neurotrace is a specific neuronal marker

Neurotrace is a specific neuronal stain and does not colocalize with glial markers. Left, confocal microscopy (scale bar: $500 \mu \mathrm{m}$ ) of sections double-labeled with Neurotrace and astroglia (top, anti-GFAP), microglia (center, anti-CD11B), oligodendroglia markers (bottom, anti-OMgp). Right panel shows inset magnifications (scale bar: $150 \mu \mathrm{m}$ ).

Click here for file [http://www.biomedcentral.com/content/supplementary/1750-1326-5-5S2.pdf]

\section{Acknowledgements}

We wish to thank Dr. Ariel Reyes (Universidad Diego Portales, Santiago, Chile) for technical advise about stereotaxic surgery, and Waldo Cerpa and Jeniffer Serrano for their collaboration in the initial steps of this study. This work was supported by DIPUC, FUNDACION ANDES, FONDAP Center for Biomedicine (13980001), CARE (Conicyt PFB12/2007), FONDECYT 1040799, 1085273, and MINREB (Millennium Center for Regenerative Biology).

\section{Author details}

'Department of Physiology, Neurobiology Unit, Center of Ageing and Regeneration (CARE), Nucleus Millennium in Regenerative Biology (MINREB), Faculty of Biological Sciences, Pontificia Universidad Catolica de Chile, Alameda 340, CP 8331010, Santiago, Chile. ' ${ }^{2}$ epartment of Cellular Biology, Center of Ageing and Regeneration (CARE), Faculty of Biological Sciences, Pontificia Universidad Catolica de Chile, Alameda 340, CP 8331010, Santiago, Chile. ${ }^{3}$ Current address: Department of Neurobiology, University of Pittsburgh, Pittsburgh, PA, 15260, USA.

\section{Authors' contributions}

OML and JCM participated in design and performed all the experiments. CP participated in design and performed the analysis of the number of total neurons in healthy brains. OML and FCB drafted the manuscript. FCB conceived and coordinated the study and participated in design of all the experiments. $\mathrm{NCl}$ helped to coordinate the axotomy experiments and the manuscript drafting and critically reviewed the drafts. All authors read and approved the manuscript.

\section{Competing interests}

The authors declare that they have no competing interests.

Received: 3 August 2009

Accepted: 19 January 2010 Published: 19 January 2010

\section{References}

1. Sofroniew MV, Galletly NP, Isacson O, Svendsen CN: Survival of adult basal forebrain cholinergic neurons after loss of target neurons. Science 1990, 247:338-342.

2. Conner JM, Culberson A, Packowski C, Chiba AA, Tuszynski MH: Lesions of the Basal forebrain cholinergic system impair task acquisition and abolish cortical plasticity associated with motor skill learning. Neuron 2003, 38:819-829.

3. Conner JM, Chiba AA, Tuszynski MH: The basal forebrain cholinergic system is essential for cortical plasticity and functional recovery following brain injury. Neuron 2005, 46:173-179.

4. Voytko ML, Olton DS, Richardson RT, Gorman LK, Tobin JR, Price DL: Basal forebrain lesions in monkeys disrupt attention but not learning and memory. J Neurosci 1994, 14:167-186.

5. Hasselmo ME: The role of acetylcholine in learning and memory. Curr Opin Neurobiol 2006.

6. Gage FH, Armstrong DM, Williams LR, Varon S: Morphological response of axotomized septal neurons to nerve growth factor. J Comp Neurol 1988, 269:147-155.

7. Hefti F: Nerve growth factor promotes survival of septal cholinergic neurons after fimbrial transections. J Neurosci 1986, 6:2155-2162.

8. Armstrong DM, Terry RD, Deteresa RM, Bruce G, Hersh LB, Gage FH: Response of septal cholinergic neurons to axotomy. J Comp Neurol 1987, 264:421-436.

9. Naumann T, Straube A, Frotscher M: Recovery of ChAT immunoreactivity in axotomized rat cholinergic septal neurons despite reduced NGF receptor expression. Eur J Neurosci 1997, 9:1340-1349.

10. Naumann T, Peterson GM, Frotscher M: Fine structure of rat septohippocampal neurons: II. A time course analysis following axotomy. J Comp Neurol 1992, 325:219-242. 
11. Hagg T, Manthorpe M, Vahlsing HL, Varon S: Delayed treatment with nerve growth factor reverses the apparent loss of cholinergic neurons after acute brain damage. Exp Neurol 1988, 101:303-312.

12. Williams LR, Varon S, Peterson GM, Wictorin K, Fischer W, Bjorklund A, Gage FH: Continuous infusion of nerve growth factor prevents basal forebrain neuronal death after fimbria fornix transection. Proc Natl Acad Sci USA 1986, 83:9231-9235.

13. Tuszynski MH, Armstrong DM, Gage FH: Basal forebrain cell loss following fimbria/fornix transection. Brain Res 1990, 508:241-248.

14. Korsching S, Auburger G, Heumann R, Scott J, Thoenen H: Levels of nerve growth factor and its mRNA in the central nervous system of the rat correlate with cholinergic innervation. Embo J 1985, 4:1389-1393.

15. Shelton $\mathrm{DL}$, Reichardt LF: Studies on the expression of the beta nerve growth factor (NGF) gene in the central nervous system: level and regional distribution of NGF mRNA suggest that NGF functions as a trophic factor for several distinct populations of neurons. Proc Natl Acad Sci USA 1986, 83:2714-2718.

16. Schweitzer JB: Nerve growth factor receptor-mediated transport from cerebrospinal fluid to basal forebrain neurons. Brain Res 1987, 423:309-317.

17. Kromer LF, Bjorklund A, Stenevi U: Regeneration of the septohippocampal pathways in adult rats is promoted by utilizing embryonic hippocampal implants as bridges. Brain Res 1981, 210:173-200.

18. Conner JM, Varon S: Distribution of nerve growth factor-like immunoreactive neurons in the adult rat brain following colchicine treatment. J Comp Neurol 1992, 326:347-362.

19. Zee van der CE, Hagg T: Delayed NGF infusion fails to reverse axotomyinduced degeneration of basal forebrain cholinergic neurons in adult p75(LNTR)-deficient mice. Neuroscience 2002, 110:641-651.

20. Fischer W, Bjorklund A: Loss of AChE- and NGFr-labeling precedes neuronal death of axotomized septal-diagonal band neurons: reversal by intraventricular NGF infusion. Exp Neurol 1991, 113:93-108.

21. Wilcox BJ, Applegate MD, Portera-Cailliau C, Koliatsos VE: Nerve growth factor prevents apoptotic cell death in injured central cholinergic neurons. J Comp Neurol 1995, 359:573-585.

22. Kafri T, Randolph-Moore L, Verma IM, Gage FH: Bcl-xL protects adult septa cholinergic neurons from axotomized cell death. Proc Natl Acad Sci USA 1998, 95:2603-2608.

23. Kaplan DR, Miller FD: Neurotrophin signal transduction in the nervous system. Curr Opin Neurobiol 2000, 10:381-391.

24. Bamji SX, Majdan M, Pozniak CD, Belliveau DJ, Aloyz R, Kohn J, Causing CG, Miller FD: The p75 neurotrophin receptor mediates neuronal apoptosis and is essential for naturally occurring sympathetic neuron death. J Cell Biol 1998, 140:911-923.

25. Brann AB, Tcherpakov M, Williams IM, Futerman AH, Fainzilber M: Nerve growth factor-induced p75-mediated death of cultured hippocampal neurons is age-dependent and transduced through ceramide generated by neutral sphingomyelinase. J Biol Chem 2002, 277:9812-9818.

26. Pagadala PC, Dvorak LA, Neet KE: Construction of a mutated pro-nerve growth factor resistant to degradation and suitable for biophysical and cellular utilization. Proc Natl Acad Sci USA 2006, 103:17939-17943.

27. Volosin M, Song W, Almeida RD, Kaplan DR, Hempstead BL, Friedman WJ: Interaction of survival and death signaling in basal forebrain neurons: roles of neurotrophins and proneurotrophins. J Neurosci 2006 , 26:7756-7766

28. Roux PP, Colicos MA, Barker PA, Kennedy TE: p75 neurotrophin receptor expression is induced in apoptotic neurons after seizure. J Neurosci 1999, 19:6887-6896

29. Harrington AW, Leiner B, Blechschmitt C, Arevalo JC, Lee R, Morl K, Meyer M, Hempstead BL, Yoon SO, Giehl KM: Secreted proNGF is a pathophysiological death-inducing ligand after adult CNS injury. Proc Natl Acad Sci USA 2004, 101:6226-6230.

30. Berse B, Szczecinska W, Lopez-Coviella I, Madziar B, Zemelko V, Kaminski R, Kozar K, Lips KS, Pfeil U, Blusztajn JK: Expression of high affinity choline transporter during mouse development in vivo and its upregulation by NGF and BMP-4 in vitro. Brain Res Dev Brain Res 2005, 157:132-140.

31. Eiden LE: The cholinergic gene locus. J Neurochem 1998, 70:2227-2240.

32. Bejanin S, Cervini R, Mallet J, Berrard S: A unique gene organization for two cholinergic markers, choline acetyltransferase and a putative vesicular transporter of acetylcholine. J Biol Chem 1994, 269:21944-21947.
33. Gibbs RB: Estrogen and nerve growth factor-related systems in brain. Effects on basal forebrain cholinergic neurons and implications for learning and memory processes and aging. Ann N Y Acad Sci 1994, 743:165-196, discussion 197-169.

34. Geula C, Mesulam M: . Cholinergic Systems and Related Neuropathological Predilection Patterns in Alzheimer's Disease New York: Raven Press Ltd 1994

35. Winkler J, Thal LJ, Gage FH, Fisher LJ: Cholinergic strategies for Alzheimer's disease. J Mol Med 1998, 76:555-567.

36. Williams B, Nelson M, Granholm AC, Coultrap S, Browning M, Curtis M: Altered NGF response but not release in the aged septo-hippocampal cholinergic system. Exp Neurol 2005, 196:30-40.

37. Koliatsos VE, Nauta HJ, Clatterbuck RE, Holtzman DM, Mobley WC, Price DL: Mouse nerve growth factor prevents degeneration of axotomized basal forebrain cholinergic neurons in the monkey. J Neurosci 1990, 10:3801-3813.

38. Salehi A, Delcroix JD, Belichenko PV, Zhan K, Wu C, Valletta JS, TakimotoKimura R, Kleschevnikov AM, Sambamurti K, Chung PP, et al: Increased App expression in a mouse model of Down's syndrome disrupts NGF transport and causes cholinergic neuron degeneration. Neuron 2006, 51:29-42.

39. Tuszynski MH, Thal L, Pay M, Salmon DP, U HS, Bakay R, Patel P, Blesch A, Vahlsing $\mathrm{HL}, \mathrm{Ho} G$, et al: A phase 1 clinical trial of nerve growth factor gene therapy for Alzheimer disease. Nat Med 2005, 11:551-555.

40. Hagg T, Fass-Holmes B, Vahlsing HL, Manthorpe M, Conner JM, Varon S: Nerve growth factor (NGF) reverses axotomy-induced decreases in choline acetyltransferase, NGF receptor and size of medial septum cholinergic neurons. Brain Res 1989, 505:29-38.

41. Stokin GB, Lillo C, Falzone TL, Brusch RG, Rockenstein E, Mount SL, Raman R, Davies P, Masliah E, Williams DS, Goldstein LS: Axonopathy and transport deficits early in the pathogenesis of Alzheimer's disease. Science 2005, 307:1282-1288.

42. Salehi A, Delcroix JD, Mobley WC: Traffic at the intersection of neurotrophic factor signaling and neurodegeneration. Trends Neurosci 2003, 26:73-80.

43. Morse JK, Wiegand SJ, Anderson K, You Y, Cai N, Carnahan J, Miller J, DiStefano PS, Altar CA, Lindsay RM, et al: Brain-derived neurotrophic factor (BDNF) prevents the degeneration of medial septal cholinergic neurons following fimbria transection. J Neurosci 1993, 13:4146-4156.

44. Naumann T, Linke R, Frotscher M: Fine structure of rat septohippocampal neurons: I. Identification of septohippocampal projection neurons by retrograde tracing combined with electron microscopic immunocytochemistry and intracellular staining. J Comp Neurol 1992, 325:207-218

45. Kermer $P$, Naumann $T$, Bender R, Frotscher M: Fate of GABAergic septohippocampal neurons after fimbria-fornix transection as revealed by in situ hybridization for glutamate decarboxylase mRNA and parvalbumin immunocytochemistry. J Comp Neurol 1995, 362:385-399.

46. Bronfman FC, Moechars D, Van Leuven F: Acetylcholinesterase-positive fiber deafferentation and cell shrinkage in the septohippocampal pathway of aged amyloid precursor protein london mutant transgenic mice. Neurobiol Dis 2000, 7:152-168.

47. Schmued LC, Stowers CC, Scallet AC, Xu L: Fluoro-Jade $C$ results in ultra high resolution and contrast labeling of degenerating neurons. Brain Res 2005, 1035:24-31.

48. Mullen RJ, Buck CR, Smith AM: NeuN, a neuronal specific nuclear protein in vertebrates. Development 1992, 116:201-211.

49. Brazelton TR, Rossi FM, Keshet Gl, Blau HM: From marrow to brain expression of neuronal phenotypes in adult mice. Science 2000, 290:1775-1779.

50. Paul CE, Vereker E, Dickson KM, Barker PA: A pro-apoptotic fragment of the p75 neurotrophin receptor is expressed in p75NTRExonIV null mice. J Neurosci 2004, 24:1917-1923.

51. Carson C, Saleh M, Fung FW, Nicholson DW, Roskams AJ: Axonal dynactin p150Glued transports caspase-8 to drive retrograde olfactory receptor neuron apoptosis. J Neurosci 2005, 25:6092-6104.

52. Dusart I, Sotelo C: Lack of Purkinje cell loss in adult rat cerebellum following protracted axotomy: degenerative changes and regenerative attempts of the severed axons. J Comp Neurol 1994, 347:211-232.

53. Snider WD, Elliott JL, Yan Q: Axotomy-induced neuronal death during development. J Neurobiol 1992, 23:1231-1246. 
54. Oliveira AL, Risling M, Deckner M, Lindholm T, Langone F, Cullheim S: Neonatal sciatic nerve transection induces TUNEL labeling of neurons in the rat spinal cord and DRG. Neuroreport 1997, 8:2837-2840.

55. Walsh GS, Orike N, Kaplan DR, Miller FD: The invulnerability of adult neurons: a critical role for p73. J Neurosci 2004, 24:9638-9647.

56. Costigan M, Mannion RJ, Kendall G, Lewis SE, Campagna JA, Coggeshall RE, Meridith-Middleton J, Tate S, Woolf CJ: Heat shock protein 27: developmental regulation and expression after peripheral nerve injury. $J$ Neurosci 1998, 18:5891-5900.

57. Nakagomi S, Suzuki Y, Namikawa K, Kiryu-Seo S, Kiyama H: Expression of the activating transcription factor 3 prevents c-Jun $\mathrm{N}$-terminal kinaseinduced neuronal death by promoting heat shock protein 27 expression and Akt activation. J Neurosci 2003, 23:5187-5196.

58. Giehl KM, Rohrig S, Bonatz H, Gutjahr M, Leiner B, Bartke I, Yan Q, Reichardt LF, Backus C, Welcher AA, et al: Endogenous brain-derived neurotrophic factor and neurotrophin-3 antagonistically regulate survival of axotomized corticospinal neurons in vivo. J Neurosci 2001, 21:3492-3502.

59. Takuma K, Baba A, Matsuda T: Astrocyte apoptosis: implications for neuroprotection. Prog Neurobiol 2004, 72:111-127.

60. Lopez-Coviella I, Berse B, Krauss R, Thies RS, Blusztajn JK: Induction and maintenance of the neuronal cholinergic phenotype in the central nervous system by BMP-9. Science 2000, 289:313-316.

61. Lopez-Coviella I, Follettie MT, Mellott TJ, Kovacheva VP, Slack BE, DiesI V, Berse B, Thies RS, Blusztajn JK: Bone morphogenetic protein 9 induces the transcriptome of basal forebrain cholinergic neurons. Proc Natl Acad Sci USA 2005, 102:6984-6989.

62. Lonn P, Zaia K, Israelsson C, Althini S, Usoskin D, Kylberg A, Ebendal T: BMP enhances transcriptional responses to NGF during PC12 cell differentiation. Neurochem Res 2005, 30:753-765.

63. Pongrac JL, Gibbs RB, Defranco DB: Estrogen-mediated regulation of cholinergic expression in basal forebrain neurons requires extracellularsignal-regulated kinase activity. Neuroscience 2004, 124:809-816.

64. Bora SH, Liu Z, Kecojevic A, Merchenthaler I, Koliatsos VE: Direct, complex effects of estrogens on basal forebrain cholinergic neurons. Exp Neurol 2005, 194:506-522.

65. Paxinos $G$, Watson $C$ : The rat brain in stereotaxic coordinates. San Diego: Academic Press, 41998.

66. Gage FH, Bjorklund A, Stenevi U: Reinnervation of the partially deafferented hippocampus by compensatory collateral sprouting from spared cholinergic and noradrenergic afferents. Brain Res 1983, 268:27-37.

67. Afford S, Randhawa S: Apoptosis. Mol Pathol 2000, 53:55-63.

68. Al-Abdulla NA, Martin $\mathrm{L}$ : Apoptosis of retrogradely degenerating neurons occurs in association with the accumulation of perikaryal mitochondria and oxidative damage to the nucleus. Am J Pathol 1998, 153:447-456.

doi:10.1186/1750-1326-5-5

Cite this article as: Lazo et al:: Axotomy-induced neurotrophic withdrawal causes the loss of phenotypic differentiation and downregulation of NGF signalling, but not death of septal cholinergic neurons. Molecular Neurodegeneration 2010 5:5.

\section{Submit your next manuscript to BioMed Central and take full advantage of:}

- Convenient online submission

- Thorough peer review

- No space constraints or color figure charges

- Immediate publication on acceptance

- Inclusion in PubMed, CAS, Scopus and Google Scholar

- Research which is freely available for redistribution

Submit your manuscript at www.biomedcentral.com/submit
Biomed Central 